\title{
Das montanhas mexicanas ao ciberespaço
}

\author{
PEDRO HENRIQUE FALCO ORTIZ
}

Aqui estamos!

Somos a dignidade rebelde, o coração esquecido da pátria!

(Subcomandante Marcos, EZLN

Quarta Declaração da Selva Lacandona, 1/1/1996)

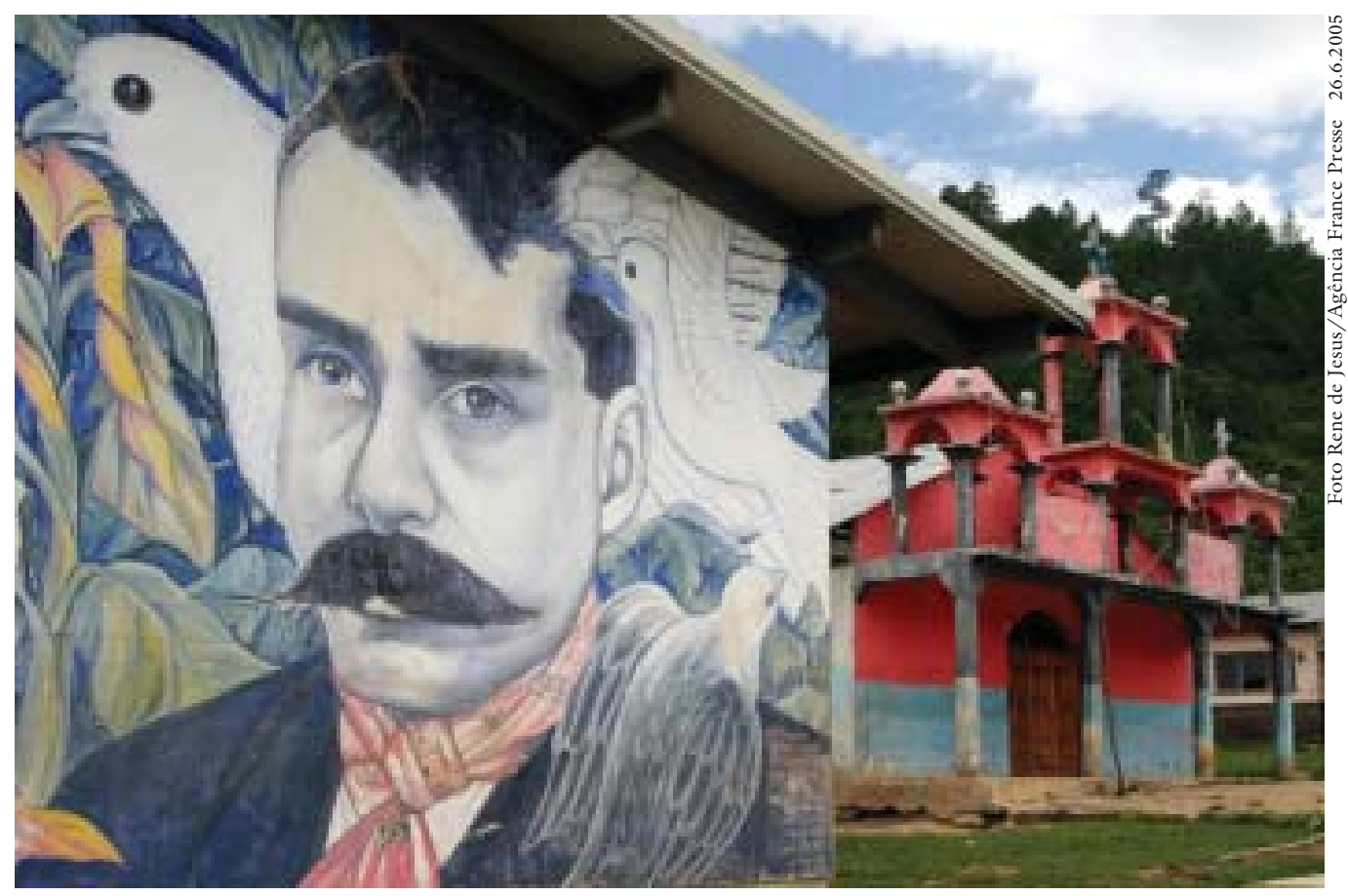

Aspecto das instalações vazias do município autônomo zapatista "La Garucha”, no México.

$\mathrm{P}$ RIMEIRO de janeiro de 1994. Em muitos lares mexicanos os champanhes estouraram comemorando a chegada do ano novo e a entrada em vigor do Nafta (North American Free Trade Agreement) ou TLC (Tratado de Livre Comércio), o acordo comercial entre Estados Unidos, Canadá e México, a tão anunciada porta para o chamado primeiro mundo, como não cansou de propagandear o governo do então presidente mexicano Carlos Salinas de Gortari, eleito em 1988, em pleito que teve o resultado contestado pela oposição ao PRI (Partido Revolucionário Institucional). Mas naquela mesma madrugada de festa, das entranhas do esquecido México profundo ${ }^{1}$, no coração da longínqua selva lacandona, milhares de mestiços e índios das etnias tzotzil, tzeltal, tojolabal, chol, mame e zoque, herdeiros da cultura maia, desceram das montanhas para ocupar várias cidades e localidades do empobrecido Estado de Chiapas, no sul 
do país, região fronteiriça com a Guatemala. Surgiram das brumas da noite como guerrilheiros do autodenominado e até então desconhecido Exército Zapatista de Libertação Nacional - EZLN, surpreendendo em suas ações-relâmpago não só à sociedade e ao governo mexicanos, mas a todo o mundo.

Em pouco tempo a notícia se espalhou. Nos dias seguintes ao levante indígena, os principais jornais do planeta estampavam em suas páginas fotos dos guerrilheiros zapatistas (ou neozapatistas), com seus rostos cobertos por pasamontañas e paliacates, as máscaras de lã e os lenços vermelhos que ocultam sua identidade. Trechos da Declaración de la Selva Lacandona ${ }^{2}$, a declaração de guerra dos rebeldes ao governo e ao exército federais foram reproduzidos em vários meios de comunicação.

Nos dois dias em que os rebeldes ocuparam e permaneceram em San Cristóbal de Las Casas, antiga capital do Estado de Chiapas, o subcomandante insurgente Marcos, chefe militar e porta-voz do EZLN, deu entrevistas a jornalistas e a correspondentes que chegavam em levas da capital federal e de várias partes do mundo. Também conversou com moradores e turistas atônitos, que não entendiam tamanha confusão na pacata cidade de arquitetura colonial. Uma viajante norte-americana quis saber como fazer para sair da cidade, pois estava de férias e queria prosseguir em seu roteiro turístico pela região, onde há sítios arqueológicos famosos, como o de Palenque. "Estamos no meio de uma guerra, minha senhora, mas podemos the dar um salvo-conduto para sair da cidade", explicava um paciente e educado mascarado, apelidado el sub $\mathrm{Marcos}^{3}$.

Apanhado de surpresa em sua ressaca primeiro-mundista, o governo mexicano não soube como reagir de imediato. Demorou alguns dias para decidir por uma contra-ofensiva militar e quando ordenou que suas tropas em Chiapas respondessem aos rebeldes, muitos guerrilheiros já haviam recuado aos seus esconderijos na selva ou nas montanhas. Mas alguns enfrentamentos armados ocorreram na cidade de Ocosingo e os zapatistas, mal armados, levaram a pior e tiveram mais de cem baixas. Manifestações civis na Cidade do México e nas principais cidades do país clamavam por um cessar-fogo e abertura de negociações entre as partes. O EZLN pedia seu reconhecido com o status de força beligerante e que suas reivindicações básicas por terra, trabalho, pão, teto, liberdade, dignidade e justiça fossem atendidas, ou pelo menos consideradas.

O armistício só veio uma semana depois. Por sugestão dos zapatistas e pressões da sociedade civil, o governo aceitou negociar com os rebeldes e reconheceu como mediador D. Samuel Ruiz García, então bispo de San Cristóbal de las Casas. Tatic Samuel, padrecito, em língua tzotzil, era um padre conservador do Estado de Guanajuato, mas a partir de sua chegada a Chiapas nos anos de 1970 e de seu contato com as comunidades indígenas e camponesas, transformou-se em expoente da Teologia da Libertação e da defesa dos direitos humanos no México. A Conai - Comissão Nacional de Intermediação, presidida por Ruiz e integrada por intelectuais, artistas e dirigentes sociais, impulsionou as 
primeiras negociações entre os rebeldes zapatistas e o governo federal, a partir de fevereiro de 1994, e manteve-se como a principal instância negociadora do processo de paz até sua dissolução, em 1997.

\section{Da selva ao ciberespaço}

Comunicados assinados pelo Comitê Clandestino Revolucionário Indígena - CCRI, instância máxima do EZLN, e pelo subcomandante Marcos, correm o mundo há mais de dez anos. A Declaração da Selva Lacandona foi publicada na íntegra pelo diário mexicano La Jornada já no dia seguinte ao levante armado, em 2 de janeiro, e prontamente foi traduzida ao inglês e outros idiomas. Foi o primeiro documento da revolta zapatista, rapidamente colocado em alguns endereços de conferências eletrônicas sobre o México nas redes de comunicação por computadores, podendo ser lida ao mesmo tempo por um ativista de direitos humanos na Califórnia, uma dona de casa alemã ou um estudante japonês.

Uma eficiente rede de comunicação e solidariedade, utilizando os recursos do correio eletrônico e das redes de comunicação via Internet foi tecida em todo o mundo por ativistas de direitos humanos, simpatizantes da causa zapatista e movimentos sociais alternativos. Desde as primeiras semanas da aparição pública do EZLN, os comunicados da comandância zapatista e os do subcomandante Marcos, repletos de referências culturais, citações literárias, mitologia indígena e com fartas doses de bom humor, já podiam ser acessados eletronicamente de diversas partes do planeta a partir de listas de discussão sobre Chiapas na Internet, que eram abastecidas diariamente com informações frescas sobre o que acontecia na zona de conflito.

Nos endereços eletrônicos que começaram a funcionar como diretórios sobre Chiapas, passaram a circular comentários, análises sobre o conflito, especulações sobre a origem do EZLN e até sobre a identidade de Marcos. Boatos de que ele seria um padre levaram até um religioso da hierarquia jesuíta nos Estados Unidos a entrar na rede e a desmentir qualquer ligação com sua ordem.

Além de suas características bastante peculiares como movimento político e armado, apelidado pelo escritor mexicano Carlos Fuentes e pela mídia internacional como primeira guerrilha da era pós-moderna ou pós-muro de Berlim, o EZLN rapidamente transformou-se também em importante fenômeno comunicacional ou mediático. A habilidade de Marcos como comunicador e conhecedor dos meios de comunicação, a capacidade dos zapatistas em se manterem na mídia e o interesse despertado em todo o mundo, alimentando constantemente as redes eletrônicas com informações de e sobre Chiapas, fizeram com que as reivindicações básicas dos insurgentes zapatistas e a realidade das populações indígenas da região circulassem em escala global, chamando a atenção não só da sociedade mexicana, mas de grande parte da população mundial para as demandas seculares daqueles povos até então esquecidos.

Marcos tornou-se o primeiro super-herói da Internet, como analisaram alguns ativistas de mídia e destacou um site norte-americano de web art zapatista. 
Com um alcance infinitamente superior ao dos seus velhos fuzis e espingardas que, como eles mesmos reconhecem, não têm condições de enfrentar o poderio bélico do exército federal mexicano, os zapatistas e seus comunicados protagonizaram também desde aquele surpreendente $1^{\mathrm{O}}$ de janeiro uma guerra de e pela informação, praticamente em tempo real, on-line $e^{4}$.

O governo mexicano, que durante quase sete décadas de monopólio do PRI no poder tentou exercer um controle explícito e reconhecido poder de influência sobre grande parte dos meios de comunicação do país, sobretudo quando se tratava da televisão e o megaimpério Televisa, teve que recuar quando as notícias vindas diretamente da zona de conflito desmentiram a versão oficial de que não havia ataques do exército federal sobre áreas civis. Os comunicados zapatistas e as denúncias dos organismos humanitários circulavam pelo ciberespaço quase em tempo real, abastecendo os ativistas de direitos humanos em todo o mundo e a imprensa internacional antes que os comunicados oficiais do governo.

Até a poderosa rede Televisa, que por suas ligações com o governo mexicano inicialmente foi proibida pelos rebeldes de entrar com suas equipes no território controlado pelo EZLN, acabou abrindo espaço em seu noticiário para as reivindicações zapatistas durante as tentativas de negociações de paz, entre fevereiro e março de 1994, em San Cristóbal de Las Casas, porque todos os principais meios de comunicação, nacionais e estrangeiros, estavam lá e davam a notícia. E quando as negociações foram encerradas sem acordos de paz concretos, um comunicado do EZLN deu a volta ao mundo contestando a versão oficial divulgada pelo governo, de que acordos haviam sido firmados.

Além da hábil utilização das redes eletrônicas de comunicação, o movimento zapatista soube trabalhar sua imagem no restante da mídia, conseguindo efeitos surpreendentes. As ações armadas de $1^{\circ}$ de janeiro de 1994 não foram ingenuamente coincidentes com a data de entrada em vifgos do TLC-Nafta e eles deixaram clara essa intenção em seus primeiros pronunciamentos públicos. Enquanto o México ufanista comemorava o acordo, a face oculta do México milenar ganhava espaço na mídia, com suas raízes indígenas, seus rostos cobertos e suas reivindicações inegavelmente justas, aparecendo nas telas de TV e nas primeiras páginas de jornais e revistas como os novos ícones da revolta popular em tempos pós-modernos.

\section{Aqui estamos...}

Um guia turístico das ruínas de Palenque, no norte do estado de Chiapas, costuma contar uma história. Uma turista, depois de ficar boquiaberta com a visão esplendorosa das pirâmides maias, virou-se para o guia e disse: "Os edifícios são maravilhosos, mas onde foi parar toda a gente que os construiu?" Ela estava falando justamente com um descendente da cultura Maia, lembra ironicamente o guia, que respondeu: "Nós ainda estamos aqui, nós nunca fomos embora". Em quase toda a América há vestígios de culturas pré-colombianas que resistiram ao tempo, ou por ele mesmo foram preservadas, dos saques, da destruição 
total. Ruínas de civilizações desaparecidas, como as de Palenque, provocam a curiosidade de pesquisadores, sejam eles historiadores, arqueólogos, antropólogos, paleontólogos, botânicos, urbanistas. Mas teriam mesmo desaparecido os criadores de maravilhas arquitetônicas como as pirâmides maias e outros tesouros encontrados ainda hoje do norte ao sul do continente?

A resposta do guia turístico indígena é uma boa pista para dizermos que não. O exemplo vindo de Palenque talvez possa servir para elucidar um dos aparentes paradoxos desse quebra-cabeças: ao mesmo tempo em que inúmeros pesquisadores investigam as causas do colapso da civilização maia clássica, os próprios descendentes maias estão à sua volta. Aproximadamente um milhão de indígenas de origem maia vivem atualmente no Estado de Chiapas e cerca de cinco milhões estão espalhados pela Península de Yucatán, no México, e em comunidades rurais de Belize, Guatemala, Honduras e El Salvador. Étnica e culturalmente, são descendentes do mesmo povo que criou uma das mais fascinantes civilizações da Meso-América. São herdeiros das pirâmides, observatórios, palácios e centros rituais de Palenque, Tulum, Chichen-Itzá, Uxmal, El Tikal, Copan e dos códices maravilhosos que escaparam das fogueiras espanholas e hoje estão a salvo em museus.

Em uma conversa com jornalistas, o comandante Tacho, uma das principais lideranças indígenas zapatistas, foi indagado sobre quanto tempo o EZLN conseguiria resistir às pressões militares e à guerra de baixa intensidade movida contra eles pelo governo federal e os grupos paramilitares locais. "Nossos antepassados resistiram por quinhentos anos. Podemos resistir outros quinhentos, porque não temos pressa", foi sua resposta.

Em Chiapas, onde pelo menos um terço da população de cerca de 3,5 milhões de pessoas é indígena e mais da metade é mestiça, ainda impera um racismo de tempos coloniais. Até duas ou três décadas atrás, índios não podiam andar pelas calçadas de San Cristóbal, a cidade que leva em seu nome o sobrenome de Frei Bartolomé de Las Casas, dominicano que, no século XVI, desafiou a própria Igreja por discordar de que os índios fossem bichos e devessem ser tratados como tais. Las Casas foi ameaçado de morte e expulso de Chiapas pelos coletos, espanhóis ou criollos (mestiços) da época. Os auto-intitulados coletos de hoje, moradores brancos ou mestiços da velha cidade colonial continuam, em grande parte, a não reconhecer nos índios sua humanidade plena ou pelo menos seu direito à cidadania e à autodeterminação.

Infortúnios e contradições de uma terra rica e povo pobre. Em Chiapas, estão as maiores reservas de água potável do México, sobretudo na selva lacandona, como em montes Azules, onde rios caudalosos guardam o maior potencial para geração hídrica de energia elétrica. Também o subsolo chiapaneco é privilegiado. Lá estão as maiores reservas estratégicas de petróleo, gás natural e urânio do país. Acima da terra, uma grande diversidade florestal em madeiras nobres. Sem contar a biodiversidade de fauna e flora. Mas a maioria da população de Chiapas, 
indígena ou mestiça, padece das doenças mais primárias. Crianças morrem de diarréia, desidratação e outras enfermidades facilmente evitáveis com saneamento básico e comida.

Os indígenas descendentes do maias suportaram séculos de perseguições e exclusão. Foram expulsos de suas terras originais e empurrados para as montanhas ou a selva. Resistiram, esperaram, e, em 1994, deram o seu grito de $\Upsilon_{a}$ basta! Como escreveu Marcos, “[...] aqui estamos. Somos a dignidade rebelde, o coração esquecido da pátria" 5 .

\section{"Para todos, tudo..."}

O EZLN tem se mostrado ao mundo desde sua surpreendente aparição pública, como um movimento armado sui generis, que não se encaixa em classificações ou rótulos normalmente atribuídos aos grupos guerrilheiros ou a organizações políticas de esquerda e movimentos sociais.

$\mathrm{Na}$ prática política zapatista convergem a cosmovisão das comunidades indígenas de origem maia, que são suas bases de apoio civis, com seu histórico de resistência; a organização e as formas de luta dos camponeses mexicanos; o pensamento teórico renovado de uma esquerda democrática, não dogmática e a participação cidadã da chamada sociedade civil, que luta por transformações radicais pela via pacífica ${ }^{6}$.

Os zapatistas são, ao mesmo temp,o um grupo armado com amplas bases sociais e um movimento popular que contesta as concepções tradicionais da política. Um movimento armado que não pretende a tomada do poder, mas sim um diálogo permanente com a sociedade civil, que possibilite um movimento maior pelas transformações sociais.

As ações políticas do EZLN estão sustentadas também numa concepção de democracia que parte da experiência das comunidades indígenas e projeta-se em nível nacional, fazendo a crítica às limitações do atual modelo partidário-eleitoral e propondo novas formas de luta política que combatam radicalmente a exclusão social. Os zapatistas não têm respostas para todos os problemas. Não têm programas de governo, até mesmo porque não aspiram à tomada do poder, no que são incompreendidos e criticados por setores sociais e da esquerda partidária-eleitoral que não concebem luta social que não seja pelo poder. Anárquicos, libertários, utópicos, os zapatistas têm uma visão não dogmática e mutável das suas próprias concepções e não se autodefinem como vanguarda política nem defendem a luta armada como único caminho possível. São originais em seus métodos e objetivos, e insistem na participação da sociedade civil em um projeto maior de mudanças, onde eles seriam mais um ator, não os únicos protagonistas.

Entre os aparentes paradoxos do movimento zapatista, o subcomandante Marcos afirmou - para mais de seis mil representantes da sociedade civil, reunidos no Aguascalientes de Guadalupe Tepeyac, em plena selva Lacandona em agosto de 1994 - em seu discurso à Convenção Nacional Democrática, que as armas do EZLN aspiravam a ser inúteis um dia: “[...] não é nosso tempo, não é a 
hora das armas. Ficaremos de lado, mas não iremos embora. Esperaremos até que se abra o horizonte ou não sejamos mais necessários [...] Lutem. Lutem sem descanso. Lutem e derrotem o governo. Lutem e derrotem-nos. Nunca será tão doce a derrota se o trânsito pacífico para a democracia, a dignidade e a justiça resultar vencedor"7.

As armas do EZLN querem ser inúteis algum dia, não mais necessárias. A prática política original dos zapatistas, sua criatividade nas ações, o discurso não excludente nem dogmático, a simplicidade de suas reivindicações, têm possibilitado uma ampla articulação do zapatismo armado com sua cara-metade civil. Iniciativas políticas como a Frente Zapatista (FZLN), os fóruns nacionais e encontros intercontinentais, abriram canais de diálogo com a sociedade civil dentro e fora do México e têm sido propulsores da continuidade do movimento, da sua resistência em condições tão adversas e do seu crescimento para fora dos limites geográficos de Chiapas.

Talvez, sem essa combinação de resistência das comunidades e das bases indígenas do EZLN com a articulação de uma ampla rede de relações políticas e de solidariedade nacional e internacional, o movimento zapatista já teria sido mortalmente golpeado pelo governo e o exército mexicanos. Sua força nunca esteve nem estará nas armas ou na guerra de guerrilhas, e provavelmente por isso a lógica militar que o governo mexicano adotou para tentar vencer o EZLN tem se mostrado incapaz de derrotá-lo.

No campo da luta política o zapatismo é vitorioso, porque conseguiu sobreviver e se expandir, mesmo enfrentando todo o peso da guerra de baixa intensidade e suas conseqüências perversas para suas bases de apoio. Também ganhou rounds importantes na batalha pela comunicação, com uma presença na mídia nunca antes alcançada por nenhum outro movimento armado latino-americano nos últimos tempos. Como disseram desde o princípio, seu movimento é também uma "guerra pela palavra, contra a exclusão e o esquecimento" da população indígena marginalizada.

Além disso, a estratégia de comunicação do EZLN, combinada às ações de solidariedade da sociedade civil, possibilitou o surgimento de uma rede que, valendo-se dos recursos tecnológicos da virada do século, cumpre um papel fundamental na guerra contra a desinformação e articula agora muitos outros movimentos sociais ao redor do mundo numa espécie de Rede Intercontinental de Comunicação Alternativa, que conecta, através da Internet, cidadãos e organizações que também estão dizendo o seu Ya Basta! de variadas formas e em distintos lugares do planeta.

O futuro do zapatismo, sua conversão ou não à luta política pacífica e sua sobrevivência são incógnitas que irão se resolvendo com o tempo. O conflito em Chiapas mostra-se cada vez mais uma guerra de baixa intensidade de longa duração - com todos os outros conflitos paralelos que ocorrem no estado - e de difícil solução, pelo menos dentro da lógica militar que o governo vem adotando. 


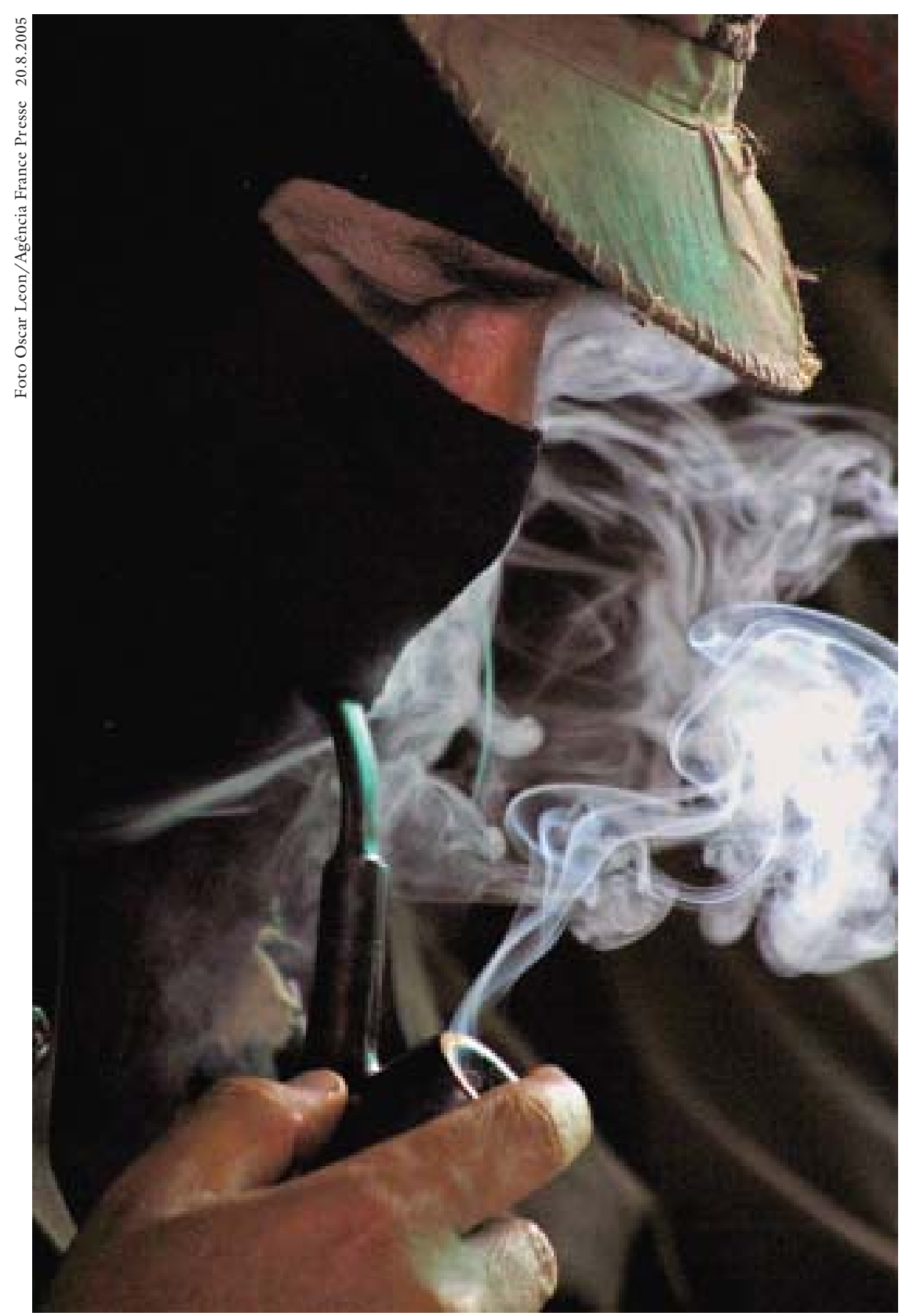

Subcomandante Marcos, lider do EZLN.

Pode ser que o EZLN desapareça como grupo armado, por decisão sua ou por uma opção militar radical do governo federal e suas forças armadas. Pode ser que cresça ainda mais como força política articulada com outros movimentos sociais. Há muitos horizontes possíveis.

Nestes mais de dez anos de resistência, as iniciativas políticas do zapatismo, sempre generosas e inclusivas, estendem a todo momento pontes de diálogo com a chamada sociedade civil, seja a mexicana ou a planetária. Foi assim com a Convenção Nacional Democrática e o incrível barco perdido na selva lacandona, o primeiro Aguascalientes de Guadalupe Tepeyac, em 1994. Depois, com o lança- 


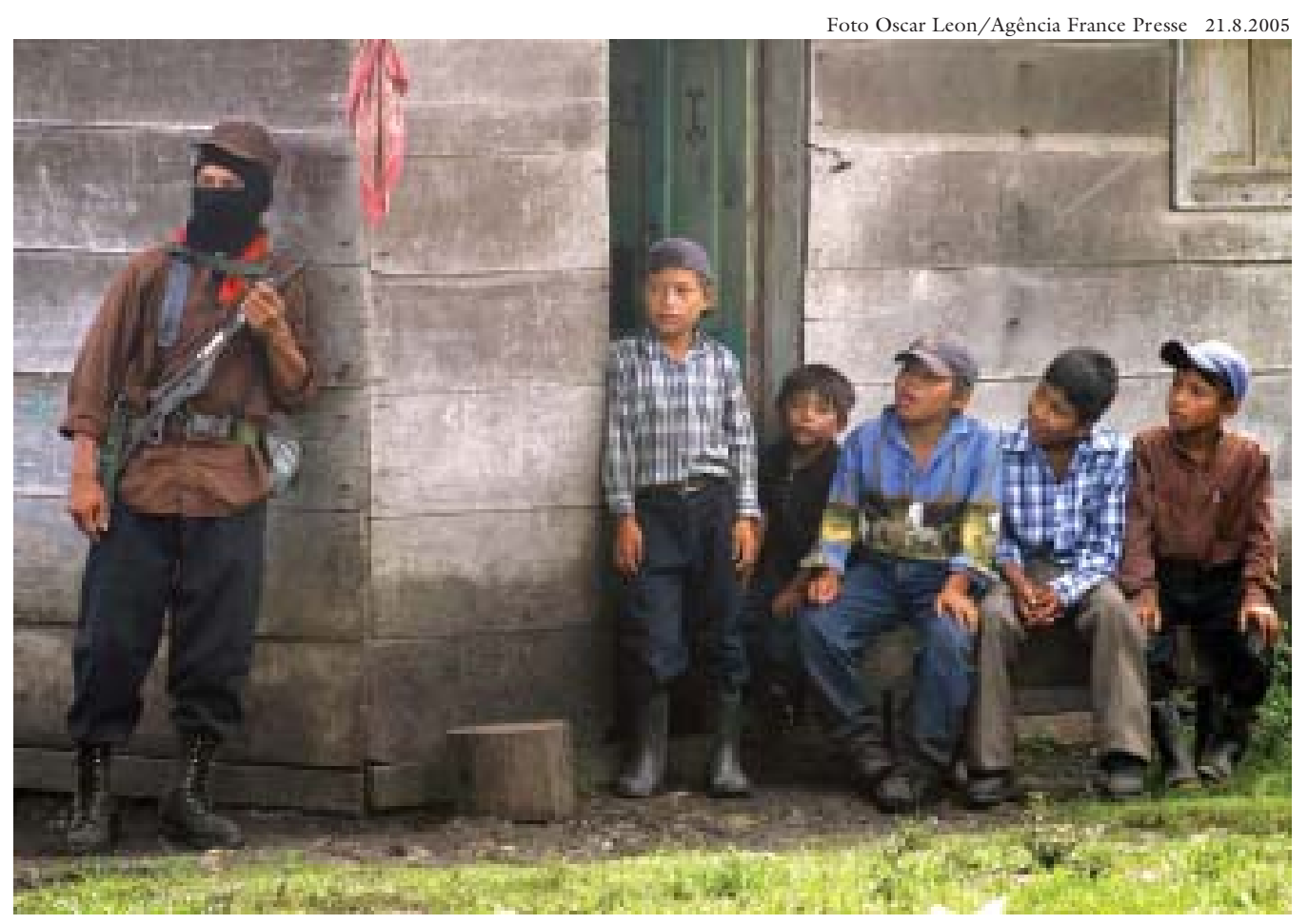

Crianças indígenas mexicanas observam soldado do EZLN em Chiapas, México.

mento da Frente Zapatista (FZLN) e o impulso para a criação do Congresso Nacional Indígena (CNI). Em seguida, o Primeiro Encontro Intercontinental pela Humanidade e contra o Neoliberalismo, o intergalático, que reuniu milhares de pessoas nos cinco Aguascalientes do território zapatista, em 1996.

Desde então, lutam pelo cumprimento dos Acordos de San Andrés e pela aprovação da Lei de Direitos e Cultura Indigenas, que havia sido negociada com os representantes do governo mas foi modificada e mutilada pelo Congresso Nacional mexicano, já na era do atual presidente, Vicente Fox. Em resposta a essa manobra da classe política, os zapatistas convocaram novamente a sociedade civil e realizaram, em março e abril de 2001, a impressionante Marcha Indígena, de mais de mil quilômetros, de Chiapas até a Cidade do México. Lá, permaneceram por duas semanas lideranças do EZLN como Marcos, comandantes indígenas e centenas de militantes e bases de apoio, reivindicando seus direitos. Líderes do movimento discursaram da tribuna de honra do Congresso Nacional.

Em Chiapas, o movimento zapatista aposta, desde 1997, na criação dos municípios autônomos, resposta prática e ousada ao não cumprimento dos primeiros acordos de San Andrés pelo governo. Enfrentam a ameaça constante dos grupos paramilitares e ainda encontram forças para colocar no ar, desde agosto de 2003, a sua Rádio Insurgente, que pode ser acessada pela Internet. Também enterraram os cinco Aguascalientes que deveriam ter a participação efetiva da sociedade civil e brindaram as suas comunidades de apoio com os novos Caracoles, centros políticos e culturais para impulsionar o sistema de governo autônomo implementado no território zapatista, denominado Juntas de Bom Governo. 
Surpreendendo os desavisados, que esperam do movimento zapatista estratégias cartesianas de ação social e política, ou deixando desorientados seus críticos e mesmo seus apoiadores, o EZLN alterna períodos de intensa atividade, com presença constante na mídia a outros de absoluto silêncio, em que parece desaparecer. Foi assim na época da eleição presidencial de 2000, quando o PRI foi derrotado pela oposição conservadora do PAN-Partido de Ação Nacional, que levou Vicente Foz ao poder. Vários segmentos sociais e correntes de esquerda cobravam dos zapatistas um posicionamento sobre o processo eleitoral, alguns até pedindo sua declaração de voto em algum candidato do espectro político progressista. Foram meses de silêncio. Às vésperas da eleição, um comunicado metafórico do EZLN dava a entender que eles desdenhavam o processo eleitoral e as mirabolantes promessas de campanha dos candidatos.

Marcos, que por ser mestiço é o porta-voz do movimento, o tradutor entre dois mundos, como ele mesmo se definiu, incorpora em seus comunicados a narrativa mítica das comunidades indígenas com finas ironias ao sistema político vigente, críticas ácidas ao neoliberalismo e citações literárias de seus escritores preferidos, entre os quais Cervantes, Antonio Machado, Fernando Pessoa, Cortázar, Saramago. Também a imaginação e a generosidade política dos zapatistas, com suas propostas inclusivas lançadas sempre em direção à sociedade civil, estão presentes nos textos de Marcos, que dialogam o tempo todo com a tradição e o universo cultural das comunidades indígenas chiapanecas, com figuras míticas ou lendárias, como o velho Antonio e o besouro quixotesco, Don Durito de La Lacandona.

Os comunicados zapatistas, que saem das comunidades isoladas no meio da selva e ganham o ciberespaço, nas listas de discussão e páginas da Internet sobre o EZLN e o conflito em Chiapas, são sempre aguardados com curiosidade. Como recentemente, em junho de 2005, quando um novo período de silêncio foi interrompido com um alerta vermelho nas comunidades zapatistas que deixou muita gente apreensiva, temendo por nova investida militar, do EZLN ou contra ele. Os Caracoles em municípios autônomos foram fechados para os freqüentadores externos às comunidades, os observadores nacionais e estrangeiros que lá estavam foram retirados e, só um mês depois, veio a palavra zapatista na forma da Sexta Declaração da Selva Lacandona, extensa e detalhada, em que o movimento refaz seu percurso histórico, elabora novo diagnóstico da situação política e social do país, reafirma suas propostas e lança mais um convite-provocação à sociedade civil, agora para uma ampla consulta nacional em que pretendem ouvir os mais variados setores sociais e regiões do México com vistas à elaboração de uma nova proposta constitucional que inclua na lei maior do país os direitos e as reivindicações indígenas e dos segmentos marginalizados.

Tudo isso em novo ano eleitoral, quando o presidente da República, parte dos executivos estaduais e do legislativo, em nível nacional e regional, serão renovados. E os zapatistas reafirmam sua posição de desobediência civil, ao lança- 
rem La Otra Campaña, em alusão e oposição à campanha presidencial. Para a consulta nacional e as eleições de 2006, o EZLN propõe alianças com organizações e movimentos não eleitorais, para escutar e organizar a indignação, sem a busca do poder ou de quem aspira a ele, em clara indicação de que não apoiará nenhum candidato ${ }^{8}$.

Em quase doze anos de existência pública (ou vinte e dois desde sua criação na clandestinidade), o EZLN já deixou marcas profundamente positivas na sociedade mexicana e contribuiu para a rearticulação dos movimentos sociais, para o crescimento da oposição ao sistema de partido-estado e para que o México mestiço se reconhecesse no México indígena, historicamente marginalizado, que das profundezas milenares e com generosa utopia mostra seu rosto oculto e defende o sonho de um mundo onde caibam todos os mundos. O zapatismo reacendeu esperanças que pareciam perdidas e mostrou que ainda é possível lutar contra o esquecimento, a exclusão, o racismo, pela dignidade humana, por democracia, liberdade e justiça. Como dizem os rebeldes chiapanecos: Para todos todo, nada para nosotros.

Notas

l Gullermo Bonfil Batalia, "México Profundo - una civilización negada”, México D.F., Grijalbo, 1990.

2 Declaração da Selva Lacandona, publicada no jornal do EZLN, "El Despertador Mexicano", no diário La Jornada e outros meios de comunicação. Disponível em www.ezln.org ou www.jornada.unam.mx.

3 Uma das primeiras entrevistas de Marcos foi ao jornalista italiano Gianni Proiettis, então correspondente do "L'Unità" e que viveu vários anos em São Paulo. A entrevista foi publicada pelo jornal italiano em 4 de janeiro de 1994, reproduzida pela Agência Ansa e citada no Brasil pela Folha de S.Paulo, "Guerrilha se prepara há 10 anos, afirma líder" de 4/1/1994.

4 Em artigo intitulado "Zapatistas on-line”, Dee Dee Halleck, professora da Universidade da Califórnia em San Diego, media activist e uma das criadoras de "Paper Tiger / Deep Dish TV", de Nova York, analisa o uso da Internet pelos zapatistas e cunha a expressão: "Marcos became the first super heroe of the net", em Nacal - Report on Americas, New York, NY, set.-out. 1994, pp. 30-32. Em citação e homenagem a ela, a expressão "Zapatistas on-line" foi escolhida como título da minha dissertação, Pedro H. Falco Ortiz. "Zapatistas on-line: uma análise sobre o EZLN e o conflito em Chiapas, sua presença na Internet e a cobertura da imprensa mexicana, argentina e brasileira". Prolam-USP, São Paulo, 1997.

5 Quarta Declaração da Selva Lacandona, Subcomandante Marcos, CCRI-CG do EZLN, 1/1/1996, disponível em www.ezln.org

6 Luis Javier Garrido, "La practica política zapatista”, em La Jornada, 28/6/1997; Carlos Montemayor, "La rebelión indígena", em La Jornada Semanal, suplemento cultural do diário La Jornada, 9/2/1997; Yvon Le Bot, "El reto del EZLN: sus obsesiones no bastan como propuesta para el México del siglo 21 - el sociólogo francés Yvon Le Bot desentraña 'El sueño zapatista'”, em revista Proceso, 20/4/1997. 
7 Discurso de encerramento da CND - Convenção Nacional Democrática, Aguascalientes de Guadalupe Tepeyac, agosto de 1994, disponível em: www.ezln.org.

8 Sexta Declaração da Selva Lacandona, jul. 2005, disponível em www.chiapas.indymedia.org

Referencias bibliográficas

BATALLA, Guillermo Bonfil. "México profundo - una civilización negada". México D.F., Grijalbo, 1990.

CASTAÑEDA, Jorge C. "Sorpresas te da la vida - México 1994”. México, D.F., Nuevo Siglo/ Aguilar, 1994.

“CHIAPAS”, Instituto de Investigaciones Económicas, Universidad Nacional Autónoma de México (Unam), México D.F., Ediciones Era, 1995.

DELARBRE, Raúl Trejo. “Chiapas, la comunicación enmascarada” México, D.F., Diana, 1994.

"Democracia y Justicia" (Reseña, posición de las partes y documentos de resultado) Diálogo de Sakamch'en entre el EZLN y el Gobierno Federal, Mesa 2, Fase 2. CeAcatl,A.C., México, D.F., 1996.

"EZLN - Documentos y Comunicados -1o. de enero/8 de agosto de 1994. Prólogo de Antonio García de León, crónicas de Carlos Monsiváis y Elena Poniatowska. México, D.F., Era, 1994.

FAZIO, Carlos. "Samuel Ruiz, el caminante”. México, D.F., Espasa-Calpe, 1994.

. "El tercer vínculo - de la teoría del caos a la teoría de la militarización". México, D.F., Joaquín Mortiz, 1996.

FUENTES, Carlos. "Nuevo Tiempo Mexicano". México, D.F., Nuevo Siglo/ Aguilar, 1994.

“Feliz Año Nuevo". México, D.F., Nuevo Siglo/ Aguilar, 1995.

FUSER, Igor. "México em transe: a tragédia do neoliberalismo na terra de Zapata". São Paulo, Scritta Editorial, 1995.

KATZENBERGER, Elaine (org.). "First World, Ha Ha Ha! The Zapatista Challenge". San Francisco, City Lights Books, 1995.

LA JORNADA. “Chiapas, el alzamiento”. México, D.F., La Jornada, 1994.

LEÓN, Antonio García de. "Resistencia y Utopía”. Tomos I y II (Memorial de agravios y crónica de revueltas y profecías acaecidas en la provincia de Chiapas durante los últimos 500 años de sus historia). México, D.F., Era, 1996.

MONTEMAYOR, Carlos. “Chiapas - la rebelión indígena de México”. México, D.F., Joaquín Mortiz, 1997.

ORTIZ, Pedro H. Falco. "Zapatistas on-line: uma análise sobre o EZLN e o conflito em Chiapas sua presença na internet e a cobertura da imprensa mexicana, argentina e brasileira”. Prolam-USP, São Paulo, 1997.

REED, John. "Insurgent Mexico". Em The Collected Works of John Reed. New York, Modern Library-Random House, 1995.

ROJAS, Rosa. "Chiapas, la paz violenta”. México, D.F., La Jornada, 1995. 
TAULIS, Dauno Tótoro e THIBAUT, Emiliano. Zapatistas. Buenos Aires, Librería Liberarte, 1996.

VIQUEIRA, Juan Pedro e RUZ, Mario Humberto (org.). "Chiapas, los rumbos de otra historia". México, D.F., Centro de Estudios Mayas, Instituto de Investigaciones Filológicas/Unam, 1995.

WOMACK JR., John. “Zapata y la Revolución Mexicana”. México, D.F., Siglo Veintiuno, 1969.

Alguns sites com informações sobre Chiapas e o EZLN, na Internet:

www.ezln.org (EZLN)

www.fzln.org.mx (Frente Zapatista)

www.ezlnaldf.org (Centro de Información Zapatista)

www.utexas.edu/students/nave (Acción Zapatista)

www.chiapas.hpg.com.br (Arquivo EZLN)

www.revistarebeldia.org (Revista Rebeldía)

www.enlacecivil.org.mx (Enlace Civil)

www.nap.cuhm.mx (Nuevo Amanecer Press)

www.chiapas.indymedia.org (Centro de Medios Independientes)

www.laneta.apc.org/cni/ (Congreso Nacional Indígena)

www.jornada.unam.mx (Diário La Jornada)

RESUMO - ESTE ARTIGO faz uma apanhado histórico contextualizado e uma análise comunicacional sobre o Exército Zapatista de Libertação Nacional - EZLN, que apareceu publicamente no estado mexicano de Chiapas em janeiro de 1994, a partir de sua origem indígena, com as demandas seculares dessa parcela da população marginalizada, suas peculiaridades e sua prática política, que o fazem um grupo armado bastante original dentro do contexto das lutas populares na América Latina. As estratégias políticas e de comunicação do EZLN são diferenciais importantes em relação a outras experiências guerrilheiras anteriores. Assim, analisamos também a habilidade que os zapatistas tiveram - e ainda têm - para conquistar espaço nos meios de comunicação convencionais e criar uma eficiente rede de solidariedade e comunicação, combinando as tradições seculares das comunidades indígenas, que são suas bases, aos recursos tecnológicos de meios eletrônicos como a Internet e a Web. Esta combinação criativa de iniciativas políticas bem-sucedidas, bases sociais resistentes, diálogo permanente com a chamada sociedade civil - nacional e internacional - e vitórias importantes no campo da comunicação, compensam a fragilidade militar do EZLN e possibilitam sua continuidade, mesmo no contexto militar bastante adverso em que se situa o conflito chiapaneco.

PALAVRAS-CHAVE: América Latina, Chiapas, Zapatistas, Comunicação. 
ABSTRACT - THE PRESENT article is an historical and contextualized communicational analisis on the Zapatista National Liberation Army - EZLN, that came to light the first time on january,1994, in the mexican southern state of Chiapas, with its indigenous origin, ancient struggles of the marginalized population, its own culture and political praxis that made it a very particular social movement in the context of Latin America. The polictical and communication strategies of the EZLN are important changes when we compare it to other guerrilla movements. We also analize the hability and creativity the zapatistas have to obtain media coverage and to create an eficient solidarity and communication net, mixing traditions of the indigenous communities with advanced technological resources of electronic media like the Internet and the Web. This creative combination of succesful polictical actions, social support, permanent dialogue with the civil society - nationwide and worldwide - and important winnings in the communication struggle, make compensation to the militar fragility of the EZLN and make posible its surviving, even on a very military adverse context, as is the conflict in Chiapas.

KEY-WORDS: Latin America, Chiapas, Zapatistas, Communication.

Pedro Henrique Falco Ortiz é jornalista e documentarista, diretor da TV USP (Divisão de Mídias Audiovisuais da CCS-USP) e diretor-geral do Canal Universitário de São Paulo (CNU). Realizou extensa cobertura jornalística do conflito em Chiapas, de 1995 a 1998. É mestre e doutor em Integração da América Latina - Área de Comunicação e Cultura, pelo Programa de Pós-Graduação em Integração da América Latina (Prolam) da Universidade de São Paulo. @ - phortiz@usp.br

Este artigo é uma síntese, com atualizações, da dissertação de mestrado "Zapatistas online: uma análise sobre o EZLN e o conflito em Chiapas, sua presença na Internet e a cobertura da imprensa mexicana, argentina e brasileira".

Recebido em 20.9.05 e aceito em 22.9.05. 